\title{
The Organizational-Level Communication of African LGBT Refugee Ngos on Social Media
}

\author{
Linda JeanKenix ${ }^{1}$, Olorunfemi E. Abikanlu² \\ ${ }^{1}$ Linda Jean Kenix is an Associate Professor and Head of the Media and Communication department at \\ the University of Canterbury, New Zealand \\ lindajean.kenix@canterbury.ac.nz. \\ ${ }^{2}$ Olorunfemi. E. Abikanlu is a Ph.D Research Candidate with the Media and Communication \\ department of the University of Canterbury, New Zealand \\ olorunfemi.abikanlu@canterbury.ac.nz.
}

\begin{abstract}
Due to the extraordinary odds of successful refugee status and because lesbian, gay, bisexual and transgender (LGBT) asylum seekers are often completely isolated in their search for refugee status, there is a heightened need for Non Government Organization (NGO) support networks for these individuals. LGBT asylum seekers are often ostracized by other asylum seekers from their shared homeland and can look online for support networks rather than in person. These distinctions may prove to be much more evident through social media, which have allowed marginalized groups to determine their own representation to a degree not found throughout media history. This research will examine the rate at which two LGBT organizations, both focused on Africa but from two different geographic regions, attempt to communicate on three prominent social media platforms: Facebook, Twitter and Youtube.
\end{abstract}

Keywords: social media, non government organization (NGO), lesbian gay bisexual and transgender (LGBT), refugee, communication, Africa

\section{INTRODUCTION}

Roughly forty percent of countries continue to categorize homosexuality as illegal. Punishment ranges from imprisonment, fines, sanctions, beatings, to death. However, refugee status is still granted largely on the basis of the 1951 Convention Relating to the Status of Refugees, which found that the term refugee applies only to a person who has a "well-founded fear of being persecuted for reasons of race, religion, nationality, membership of a particular social group or political opinion." Very few countries allow sexual orientation as grounds for refugee status given that applicants must prove that sexual orientation constitutes a 'particular social group or political opinion' as mandated by the 1951 Convention. There are nineteen countries that recognize persecution due to sexual orientation as a justified reason for gaining refugee status if an applicant can demonstrate a fear of persecution based on their membership in this particular social group. Canada was the first to recognize lesbian, gay, bisexual and transgender (LGBT) refugees in 1991. The proportion of refugees who seek asylum due to their sexual orientation is extraordinarily low and applications are often unsuccessful.

Due to the extraordinary odds of successful refugee status and because gay, lesbian and transgender asylum seekers are often socially isolated in their search for refugee status, there is a heightened need for non government organization (NGO) support networks for these individuals. LGBT asylum seekers are often ostracized by other asylum seekers from their shared homeland and one could surmise that they are more likely to look online for support networks, rather than seek out support in person. [1]Thus, the needs of LGBT individuals can be quite different from others seeking refugee status - and their need for asynchronous or anonymous communication online might also be quite distinct from the general refugee community. These distinctions may prove to be much more evident through social media, which have allowed marginalized groups to determine their own representation to a degree not found throughout media history.

There has been very limited research examining LGBT NGO refugee communication, whereas there has been some other broader, yet still relatively limited, research examining NGO refugee 
communication in general.[i.e. 2] However, no research could be found that examines different types of LGBT organizations to ascertain where the differences and similarities reside in communicating with community members, sharing information, building community, and encouraging action. In addition, very limited scholastic research has focussed on the experience and challenges of LGBT individuals and organizations on social networking sites. [i.e. 3] This is fundamentally important given the nature of refugees in general and the suggested heightened need for online communication amongst the LGBT community.

Hence, this study seeks to bridge this gap in scholarship and examine how two LGBT refugees NGOs use social media to organise and communicate. The growing representation and portrayal of LGBT individuals in different digital media platforms has provided opportunity for academic examination.[4] The growing numbers of different digital platforms has meant that "NGOs have more tools at their disposal than ever to sound the alarm and generate international awareness; many observers have heralded the arrival of a new era in NGO effectiveness"' 5, p. 136].This research also asks if there are differences in the communicative attempts by LGBT NGOs in different geographic regions, which have different levels of homophobia embedded in their societies? No research could be found that examines NGO organizations across strikingly different cultures to ascertain where the differences and similarities reside in communicating with community members, sharing information, building community, and encouraging action.

\section{LGBT Organizations in Mainstream and Social Media}

Various studies [6] have detailed how social media is a tool for constructive activism and a key instrument in social change. As Guo and Saxton [7 p. 63] noted, the rate of connectivity in social media, as evidenced in the likes on Facebook, subscriber rates on Youtube, and followers on Twitter, can separate "highly engaged organizations" from others that don't appear connected to their communities. Social media tools, including Face Book and Twitter, have been used in campaigns to alleviate both gender and sexual discrimination that exist in hetero normative societies, which can promote various discriminations, preconceptions and misconceptions against non-hetero normative individuals. For the purpose of this study, LGBT or "non-hetero normative" individuals were constructed as a "subversion of the ordinary," which can create or compel some sorts of imbalance to "our regularly scheduled programming" of sexual identification [8, p.133].

In response to any perceived subversion, many within a hetero normative social group have responded with vitriol when confronted with that subversion online [9]. This can then lead to varying degrees of protest on every available platform online and as Kahn \& Kellner [10, p. 93] noted:"whether by using the Internet to take part in a worldwide expression of dissent and disgust, to divert corporate agendas and militarism through the construction of free nets and new oppositional spaces and movements, or simply to encourage critical media analysis, debate, and new forms of journalistic community, the new information and communication technologies are indeed revolutionary".

Many scholars [11] have viewed the media as a platform to challenge homophobic norms in hetero normative societies. However, much research continues to remain focused on dominant European-American perspectives [12], where "non-hetero normative individuals" [13] are accepted and protected with little or no discrimination and prejudice on their sexual identities.

\section{SCOPE AND METHODOLOGY}

This study performed a comparative analysis of social media use from two organizations based in two different social environments. Various media and communication scholars [14]have relied upon qualitative methodologies to explore organizational usage of social media tools. This research quantitatively examined the rate at which two organizations 'communicated on three prominent social media: Facebook, Twitter and Youtube. This research examined two prominent international LGBT NGOs that focus on the African continent but are based in two different geographic regions.

Given the variation in global preferences for search engines, this research used Google, Bling and Yahoo, the three most prominent international Internet search engine tools to locate LGBT NGOs with a focus on the African LGBT community that have an online presence [15]. This study used search terms such as "List of LGBT Organizations in Africa," "LGBT asylum NGOs Africa," and "Africa LGBT Organizations." The resultant lists of LGBT NGOs was then thoroughly reviewed to screen out NGOs that did not have an active presence online on their websites or were not engaged on social media platforms through frequent posts and updates. 
After these extensive searches, this study focused on the Gay and Lesbian Coalition of Kenya (GALCK) based in Kenya and the Out \& Proud Diamond Group (OPDG) based in the Netherlands. The Gay and Lesbian Coalition of Kenya also appeared in the Advocate's list of four recognized LGBT NGOs in Africa 'worth supporting.' The Advocate is an online organization that "believe(s) in giving voice to all people with a refined sensibility with a diverse portfolio which includes the most established and most recognized LGBT brands in the world"[16]. Both of the LGBT NGOs selected were also in the routine practice of using different social media platforms, such as Youtube, Facebook, and Twitter, to engage directly with their community. These groups presumably used these social media in an attempt to build a global community network among the LGBT social groups they targeted and among other LGBT NGOs.

GALCK was established in 2006 and is comprised of six organizations that all exist within Kenya: Ishtar MSM, Minority Women in Action, Gay Kenya Trust, Transgender Education and Advocacy, Artists for Recognition and Acceptance, and Persons Marginalized and Aggrieved (PEMA). These six organizations run the expanse of issues and concerns facing the larger LGBT population. As an umbrella organization, GALCK has been very focused on combating HIV in the Kenyan LGBT community.

OPDG's founders are based in the Netherlands but remain focused on issues facing LGBT in Africa. The group states their mission is to "achieve equality and justice for LGBTI persons in African countries and other countries where homosexuality is not accepted. To campaign and expose the injustices the LGBT community experience in those countries. To integrate LGBTI persons who have fled persecution" [17].

This study examined the Youtube posts and Face Book and feeds of these two organizations between January 1 and December 31, 2015. The study also examined the Twitter feeds of both organizations from February $3^{\text {rd }}$ until March $4^{\text {th }}, 2016$. This truncated period of examination for Twitter feeds was due to the limited archival practices of Twitter.

The study is focused on the Face Book feed of 2015 due to the global attention given to the African LGBT communities in 2015. During this period, there was an increasing and strengthened campaign for gay civil rights across African countries, notably resulting in increased financial pledges and donations made by the United States toward LGBT advocacy in Africa through the 'Global equality fund' [18]. These campaigns prompted the visit of the head of the Roman catholic church, Pope Francis and also the President of the United States in 2015. Both world leaders addressed the hostility that many in the gay rights movement have faced across different African countries. In 2015, the President of The United States went so far as to direct American diplomats to cut foreign aid to countries that were unreceptive to the advancement of LGBT rights [19].

\section{Analysis Pathway}

This study adopts the methodological approach of Guo and Saxton [20], who examined the Twitter feeds of advocacy organizations at the organizational and message-level of analysis. This preliminary study focused solely on the organizational-level analysis, which involves a quantitative review of the various communication attempts by these LGBT NGOs on different social media platforms available through their organizational websites. The organizational-level analysis centres on an quantitative exploration of exactly how the organizations use Face book, Youtube, and Twitter in their advocacy campaigns and the extent at which these communicative tools are being employed. Thus, the organizational level of analysis measures the frequency of tweets and direct posts or messages, as well as the number of friends and followers, retweets and reposts, hyperlinks, hash tags, and mentions. Active users of social media platforms are defined as those who post messages daily or within a pattern of regular intervals of time [21].

\section{RESULT AND DISCUSSION}

The engagement on YouTube, Face book and Twitter from GALCK and OPDG were analyzed and compared in this organizational analysis for the 2015 year period. This study found that Face Book is a communication tool that was generally adopted by both organisations. The LGBT organization from the Netherlands, OPDG, had 32,993 likes, which was more than 25 times higher than the organization from Kenya, GALCK, which had 1,274 likes. (Table 1) The number of likes available on a Face Book page denotes a representation on the extent of its social status in the online environment [22]. This 
disproportionate number of Face Book likes for OPDG suggests a stronger social status. However, the number of Twitter followers was much more equal between the two organizations. OPDG, from the Netherlands, had 1,687 Twitter Followers while GALCK came very close behind with 1,219.

Table1. The Number of Face Book Likes, Twitter Followers \& YouTube Subscribers of 2 LGBT Ngos as of $5 / 01 / 2016$.

\begin{tabular}{|l|l|l|l|}
\hline LGBT NGOs & Face book & Twitter & Youtube \\
\hline GALCK & 1,274 & 1,219 & Nil \\
\hline OPDG & 32,993 & 1,687 & 4 \\
\hline
\end{tabular}

While it is a challenge to establish any difference between the likes on Face Book and followers on Twitter directly, both communication tools operate on the same principle of attention measurement in the social media sphere. The number of friends and likes indicate an approximate number of people that constitute an engaged audience and the numerical population of the online community that regularly receive messages being posted or tweeted on Face Book or Twitter respectively. The likes and followers on both social mediums also indicate the number of people and organizations that are likely to view, engage and respond to a call for action or a situation either through retweets on Twitter or shares, likes and comments on Face Book there by enabling a two-way dialogue[23]. However, it remains a challenge to analyse the intricate connection between social network sites (Face Book and Twitter) and the fundamental reasons that could account for their followership metrics [24] because the online community on social media does not summarise to information dissemination alone, but as a platform for possible engagement and interaction [25].

Recently, research has shown that videos via social networking sites have aided to build an online community, which has led to the huge success of the Youtube [26]. Regardless, this study found that Youtube was a communicative tool that was not readily adopted by the LGBT organizations under review in this study. There were few subscribers and very few video view counts on the scant videos posted on the Youtube page of these LGBT organizations. The study also found that none of the videos posted on the Youtube pages were promoted or linked to through the Face Book and Twitter pages of these LGBT organizations. This suggests that video messaging is not given as much importance for either of the LGBT organizations - regardless of geographic origin. Both organizations didn't see the moving image - at least on the Youtube platform - as central to their cause.

Table2. Twitter use for 2 LGBT NGOs between 03/02/2016 and 04/03/2016

\begin{tabular}{|l|l|l|l|l|l|l|}
\hline NGOs & Tweets & RT & Hyperlinks (HL) & Hash tags (HT) & HL $\geq 1$ & HT $\geq 1$ \\
\hline GALCK & 96 & 222 & 58 & 138 & 1 & 26 \\
\hline OPDG & 187 & 1468 & 153 & 148 & 9 & 24 \\
\hline
\end{tabular}

As noted earlier, the use of Twitter was relatively evenly spread between both organisations. This relative equality between the followers of both organisations (Table 1) - despite being housed in two very different societal conditions - may be due to the context and variance of Twitter activity from each organization (Table 2). OPDG tweeted more than twice as much as GALCK, which suggests a much higher reliance on Twitter from the ODPG organization. However, the use of Twitter - particularly in relation to hash tags - is disproportionately higher for the Kenyan based GALCK. This dependency on hash tags could be a directed emphasis on using the platform of Twitter strategically in a country with limited resources as well as homophobic pressures. The relatively low use of hash tags from OPDG suggests a one-way mode of communication that might be much more reflexive in the context of relative societal acceptance, rather than genuinely engaging discussion and reflection. Hash tags, by definition, make it easier for users of Twitter to find messages with a specific theme or content. The reliance of GALCK on this mode of communication suggests a genuine effort on their part to not only push information out (tweets) or regurgitate information from other (retweets), but insert themselves in larger discussions about LGBT individuals within a homophobic society grappling with LGBT acceptance. OPDG, on the other hand, with their relatively large amount of tweets (over double that of GALCK) and an overwhelming preponderance of retweets (1468 to GALCK's 222 retweets) suggests a rather static, one way mode of communication that was pushed out from the organization rather than between conversations happening within the Twitter sphere.

While the number of followers for both organizations was decidedly lopsided in favor of OPDG, which is based in the Netherlands (Table 1), the actual use of Face Book told a very different story (Table 3).Despite having over 25 times less likes than OPDG on Facebook, GALCK posted more than OPDG 
with far more hyperlinks and shared posts. The only area that OPDG outperformed their Kenyan counterpart was in photo posts - OPDG posted a photo with every one of their text posts, while GALCK only posted photos in a small fraction of their text posts. Clearly GALCK did not rely upon the visual nature of the the medium. This reliance on the textual word, rather than the visual image, can also be seen in their completely non existent use of Youtube (Table 1). However, outside of this rather glaring omission in their communicative strategy, the engagement and use of Face Book by GALCK suggests an organization that was intent on using the social media um as a means of outreach with broader narratives concerning LGBT individuals. OPDG did not use one hyperlink in their Face Book posts, which suggests a very insular organization that does not integrate wider discourse into organizational communication. OPDG also had zero shared posts, which again reflects a lack of engagement with the broader LGBT community.

Table3. Face Book use for 2 LGBT Ngos From 1/01/2015to 12/31/2015

\begin{tabular}{|l|l|l|l|l|}
\hline LGBT NGOs & Posts & Post + Photo & Hyperlinks & Shared Posts \\
\hline GALCK & 135 & 14 & 30 & 86 \\
\hline OPDG & 91 & 91 & 0 & 0 \\
\hline
\end{tabular}

This research suggests one organization, Out \& Proud Diamond Group (OPDG) based in the Netherlands, had a very wide reach on Face Book and to a lesser degree Twitter - but without much strategic engagement or meaningful interaction with any larger discourse on LGBT issues. Instead, OPDG relied on one-way communicative techniques that pushed content out to followers: direct posts and retweets. In contrast, a second group, the Gay and Lesbian Coalition of Kenya (GALCK), with relatively little reach on Face Book and Twitter, was disproportionately engaged in larger discussions through shared posts, hyperlinks, and hash tags. This finding suggests that GALCK, based in the hetero normative Kenyan society, was working strategically to embed their narrative into larger discussions happening throughout social media whereas OPDG, based in the relatively inclusive society of the Netherlands, simply pushed their message out without any consideration as to engagement within a broader conversation. This distinction could be due to the nature of these disparate societies. Within a more inclusive society, OPDG had no need to engage but simply to inform and promote. GALCK, on the other hand, desperately needed to insert themselves into broader conversations - not for promotion, but for education and exchange. Thus, it appears from these limited findings that the more inclusive the society, the more reliant an LGBT organization might be on singular promotion and one-way communication. Conversely, the more hetero normative the society, the more reliant an LGBT organization might be on collaborative exchange and meaningful collaboration. Thus, the country of origin may have had an impact on the organizational use of social media as a tool for communication. In one country, which is based on more inclusive societal structures, that communication was used for promotion and in another country, where restrictive hetero normative values prevail, social media was used as a tool for education, engagement and conversation.

Further studies could conduct an etymological review on the linguistic compositions of the updates and posts from these different social media platforms at the message level of analysis. Also, this study could be a pathway to the study of the discursive differences that exist on various social media platforms between the LGBT NGOs within different social and cultural structures.

\section{REFERENCES}

[1] Rodriguez, N. (2015). Strategic Communication Through Social Media by LGBTI NGOs. Paper presented at the Association for Education in Journalism and Mass Communication, San Francisco, CA. http://www.aejmc.org/home/2015/06/glbt-2015-abstracts/

[2] Greenwood, D. N. (2013). Fame, Facebook, and Twitter: How Attitudes About Fame Predict Frequency and Nature of Social Media Use. Psychology of Popular Media Culture, 2(4), 222-236. doi: 10.1037/ppm0000013

[3] Guo, C., \& Saxton, G. D. (2014). Tweeting Social Change: How Social Media Are Changing Nonprofit Advocacy. Nonprofit and Voluntary Sector Quarterly, 43(1), 57-79. doi: $10.1177 / 0899764012471585$

[4] Rodriguez, N. (2015). Strategic Communication Through Social Media by LGBTI NGOs. Paper presented at the Association for Education in Journalism and Mass Communication, San Francisco, CA. http://www.aejmc.org/home/2015/06/glbt-2015-abstracts/ 
[5] Thrall, A. T., Stecula, D., \& Sweet, D. (2014b). May We Have Your Attention Please? Human-Rights NGOs and the Problem of Global Communication. The International Journal of Press/Politics, 19(2), 135-159.

[6] Fox, J., \& Warber, K. M. (2015). Queer Identity Management and Political Self-Expression on Social Networking Sites: A Co-Cultural Approach to the Spiral of Silence. Journal of Communication, 65(1), 79-100. doi: 10.1111/jcom.12137

[7] Marwick, A., Gray, M. L., \& Ananny, M. (2014). "Dolphins Are Just Gay Sharks": Glee and the Queer Case of Transmedia As Text and Object. Television \& New Media, 15(7), 627-647.

[8] Thrall, A. T., Stecula, D., \& Sweet, D. (2014b). May We Have Your Attention Please? Human-Rights NGOs and the Problem of Global Communication. The International Journal of Press/Politics, 19(2), 135-159.

[9] Gerbaudo, P., \& Treré, E. (2015). In search of the 'we' of social media activism: introduction to the special issue on social media and protest identities. Information, Communication \& Society, 18(8), 865-867. doi: 10.1080/1369118X.2015.1043319

[10] Nair, S. (2012). Slacktivism vs. activism: social media campaigns in India : socio-political campaigns and their success through social media platforms in India

[11] Penney, J. (2015). Responding to Offending Images in the Digital Age: Censorious and Satirical Discourses in LGBT Media Activism. Communication, Culture \& Critique, 8(2), 217-234. doi: 10.1111/cccr.12086

[12] Guo, C., \& Saxton, G. D. (2014). Tweeting Social Change: How Social Media Are Changing Nonprofit Advocacy. Nonprofit and Voluntary Sector Quarterly, 43(1), 57-79. doi: $10.1177 / 0899764012471585$

[13] Joyrich, L. (2014). Queer Television Studies: Currents, Flows, and (Main)streams. Cinema Journal, 53(2), 133-139. doi: 10.1353/cj.2014.0015

[14] Mwangi, E. (2014b). Queer Agency in Kenya's Digital Media. African Studies Review, 57(02), 93-113.

[15] Kahn, R., \& Kellner, D. (2004). New Media and Internet Activism: From the 'Battle of Seattle' to Blogging. New Media \& Society, 6(1), 87-95. doi: 10.1177/1461444804039908

[16] Gorkemli, S. (2012). Coming Out of the Internet": Lesbian and Gay Activism and the Internet as a "Digital Closet" in Turkey. Journal of Middle East Women's Studies, 8(3), 63-88.

[17] Reed, J. (2005). Ellen DeGeneres: Public lesbian number one. Feminist Media Studies, 5(1), 23-36. doi: 10.1080/14680770500058165

[18] Talmor, R. (2013). "From the Margins You Push So That the Center Implodes" Queer Media in South Africa. GLQ: A Journal of Lesbian and Gay Studies, 19(3), 383-403. doi: $10.1215 / 10642684-2074548$

[19] Hughson, J., \& Free, M. (2011). Football's 'Coming Out': Soccer and Homophobia in England's Tabloid Press. Media International Australia, Incorporating Culture \& Policy(140), 117-125.

[20] Kachgal, T. M. (2011). The "Gay Comfort Level": Examining a Media Advocacy Group's Efforts to Combat Youth Homophobia. Journal of LGBT Youth, 8(1), 53-65. doi: 10.1080/ 19361653.2011.520573

[21] Talmor, R. (2013). "From the Margins You Push So That the Center Implodes" Queer Media in South Africa. GLQ: A Journal of Lesbian and Gay Studies, 19(3), 383-403. doi: 10.1215/ 10642684-2074548

[22] Nagoshi, J. L., Nagoshi, C. T., \& Brzuzy, S. i. (2013). Gender and Sexual Identity: Transcending Feminist and Queer Theory (pp. 63). Retrieved from http://canterbury.eblib.com.au/patron/ FullRecord.aspx? $\mathrm{p}=1538758$

[23] Berger, A. A. (2000). Media and communication research methods: an introduction to qualitative and quantitative approaches. Thousand Oaks, Calif: Sage Publications.

[24] Berger, A. A. (2014). Media and communication research methods: an introduction to qualitative and quantitative approaches (Vol. Thirdition.).

[25] Daymon, C., \& Holloway, I. (2011). Qualitative research methods in public relations and marketing communications (Vol. 2nd). New York, NY: Routledge.

[26] Marwick, A., Gray, M. L., \& Ananny, M. (2014). "Dolphins Are Just Gay Sharks": Glee and the Queer Case of Transmedia As Text and Object. Television \& New Media, 15(7), 627-647. 
[27] Zeckman, A. (2014, 20/05/2014). Google Search Engine Market Share Nears 68\%. Retrieved 16/01/2016, 2016, from http://searchenginewatch.com/sew/study/2345837/google-searchengine-market-share-nears-68

[28] Heremedia.com. (2015). HereMedia. Retrieved 23/11/2015, 2015

[29] Out \& Proud Diamond Group (2016). About Out \& Proud Diamond Group. Retrieved 28 April 2016 from https://www.facebook.com/opdgroup/info/?tab=page_info.

[30] Linda, H. (2015, 08/04/2015). OBAMA, HILLARY PUSH HOMOSEXUALITY ON AFRICA. On Mission. Retrieved 05/02/2016, from http://www.wnd.com/ 2015/08/ obama- hillary- pushhomosexuality-on-africa/

[31] Onishi, N. (2015, 20/12/2015). U.S. Support of Gay Rights in Africa May Have Done More Harm Than Good. The New York Times.

[32] Guo, C., \& Saxton, G. D. (2014). Tweeting Social Change: How Social Media Are Changing Nonprofit Advocacy. Nonprofit and Voluntary Sector Quarterly, 43(1), 57-79. doi: $10.1177 / 0899764012471585$

[33] Guo, C., \& Saxton, G. D. (2014). Tweeting Social Change: How Social Media Are Changing Nonprofit Advocacy. Nonprofit and Voluntary Sector Quarterly, 43(1), 57-79. doi: 10.1177/ 0899764012471585

[34] De Cristofaro, E., Friedman, A., Jourjon, G., Kaafar, M. A., \& Shafiq, M. Z. (2014). Paying for likes?: Understanding Face Booklike fraud using honeypots. Paper presented at the Proceedings of the 2014 Conference on Internet Measurement Conference.

[35] Conway, C. (2011). Internet review: Social media - Twitter and podcasting for business. International Journal of Entrepreneurship and Innovation, 12(2), 145.

[36] De Cristofaro, E., Friedman, A., Jourjon, G., Kaafar, M. A., \& Shafiq, M. Z. (2014). Paying for likes?: Understanding Face Booklike fraud using honeypots. Paper presented at the Proceedings of the 2014 Conference on Internet Measurement Conference.

[37] Strauß, N., Kruikemeier, S., van der Meulen, H., \& van Noort, G. (2015). Digital diplomacy in GCC countries: Strategic communication of Western embassies on Twitter. Government Information Quarterly, 32(4), 369-379.

[38] Cheng, X., Dale, C., \& Liu, J. (2007). Understanding the characteristics of internet short video sharing: YouTube as a case study. arXiv preprint arXiv:0707.3670.

[39] Guo, C., \& Saxton, G. D. (2014). Tweeting Social Change: How Social Media Are Changing Nonprofit Advocacy. Nonprofit and Voluntary Sector Quarterly, 43(1), 57-79. doi: 10.1177/0899764012471585. 